\title{
BMJ Case stories in general practice: a focus Open group study
}

\author{
Eirik Abildsnes, ${ }^{1}$ Signe Flottorp, ${ }^{1,2}$ Per Stensland ${ }^{1}$
}

To cite: Abildsnes $E$, Flottorp S, Stensland P. Case stories in general practice: a focus group study. BMJ Open 2012;0:e001208. doi:10.1136/bmjopen-2012001208

- Prepublication history and additional material for this paper are available online. To view these files please visit the journal online (http://dx. doi.org/10.1136/bmjopen2012-001208).

Received 28 March 2012 Accepted 12 July 2012

This final article is available for use under the terms of the Creative Commons Attribution Non-Commercial 2.0 Licence; see http://bmjopen.bmj.com

\footnotetext{
${ }^{1}$ Department of Public Health and Primary Health Care, University of Bergen, Bergen, Norway

${ }^{2}$ Norwegian Knowledge Centre for the Health Services, Oslo, Norway

Correspondence to
Dr Eirik Abildsnes,
Department of Public Health
and Primary Health Care,
University of Bergen,
Postboks 7804, N-5020
Bergen, Norway;
eabil@broadpark.no

Correspondence to Dr Eirik Abildsnes, Department of Public Health and Primary Health Care, University of Bergen, Bergen, Norway; eabil@broadpark.no
}

\section{ABSTRACT}

Objectives: To explore the interactive process of sharing case stories in small-group activity in general practice.

Design: Qualitative focus group study.

Setting: Peer-group meetings of doctors attending specialist training or continuous medical education in general practice.

Participants: Twenty female and 30 male doctors working in general practice in Norway.

Results: The storyline of case presentations included detailed stories with emotional engagement, coauthored by other group members. The stories initiated discussions and reflections concerning patients' and doctors' perspectives, medical ethics as well as clinical problems. The safe atmosphere allowed testing out boundaries of socially shared knowledge.

Conclusions: Sharing case stories in small groups in general practice initiated interaction that facilitated meaning-making, reflection and peer support.

\section{INTRODUCTION}

Case stories have a longstanding tradition in medicine. Doctors share case stories when referring patients to hospital from primary healthcare, at morning reports in hospital, and when discussing interesting or difficult cases. $^{12}$ Case stories include everyday practice, dramatic 'war stories' and anecdotes of uncommon practice. The stories aim to provide a professional audience with succinct and sufficient information to understand the specific clinical problem. ${ }^{3}$ Doctors adopt the storyline of case presentations early in their career. During case presentations students, interns and residents improve knowledge based on clinical experience, and learn the medical language, professional principles, traditions and values. ${ }^{4}$ Their supervisors evaluate their presentations based on relevance, conciseness and mastery of the medical language. ${ }^{5}$ Doctors adjust their retelling and interpretations of the patients' stories into case stories suitable for a professional audience. ${ }^{6}$

\section{ARTICLE SUMMARY}

\section{Article focus}

- Sharing case stories have longstanding traditions among doctors. General practitioners (GPS) share case stories in small-group learning.

- Socially shared knowledge is formed and maintained through dialogical thinking and communication, and affects what is being talked about and the manner by which content is framed.

- We intended to explore the interactive process of discussing case stories in peer groups of GPS.

\section{Key messages}

- Case presentations in focus groups included detailed stories with emotional engagement and co-authoring from other group members.

- The case stories initiated discussions facilitating attention to person-focused care. Case story discussions in small-group learning functioned as an arena for testing out communication strategies to be used in consultations.

Strengths and limitations

- The presence of the researchers influenced what group members chose to tell.

- Being a peer may cause blindness to aspects of the discussions that a researcher with different background would see.

- The participants discussed real case stories from their own practice.

Peer groups of general practitioners (GPs) share professional competence, experience and social role. Such socially shared knowledge has an interactive nature. It is formed and maintained through dialogical communication, and determines what is being talked about and the manner by which content is framed. ${ }^{7}$ It influences how group members speak about others, such as patients, other professionals or health authorities. Dialogues involve tension and intentions, and dealing with this implicit shared knowledge within a group is an important social skill. ${ }^{8}$ The distribution of this competence within a group may affect group dynamics, and the outcome of group discussions. Communication is affected by fear of losing face, indirect communication 
and hidden agendas. Group members may carry out unspoken, internal dialogues to try out their communication strategies before they take part in the spoken discussion. ${ }^{7}$

Research on the development of doctors' communication patterns emphasises that medical education, internship and residency influence doctors' identities in ways that affect communication with patients. ${ }^{9}$ Case-based teaching is used along with problem-based teaching in medical education, and is well suited for small-group teaching. ${ }^{10}$ Problem-based teaching focuses on a particular clinical problem, while case-based teaching focuses on a particular patient presenting with a clinical problem. In general practice case-based learning in organised peer groups is widely used. ${ }^{11-14}$ Permanent small-group activities have become an important part of continuous medical education (CME) in many countries, and can serve as supportive networks to share knowledge and clinical experience. ${ }^{15-18}$

While conducting focus group sessions among GPs to study GPs' experience with lifestyle counselling, ${ }^{19}$ we observed interesting interaction within the groups. We have not identified studies that explore the interactive process of discussing case stories. The aim of this paper is to explore and describe how peer groups of GPs interact when they share and discuss case stories.

\section{METHODS}

In Norway interns spend 6 months of their internship in general practice, and they attend to supervised peer groups in these months. In specialist training in general practice, residents (specialist candidates) attend to 3 years of participation in supervised peer groups while they work in general practice. All partners (specialists in general practice, practising physicians) attend to peer groups as a mandatory part of continuous medical education. In Norway it is required to recertify as specialist in general practice every fifth year. All groups meet four to six times a year, each meeting lasts $2-3 \mathrm{~h}$.

We invited seven established peer groups from the southern part of Norway to attend focus group sessions on lifestyle counselling. We used strategic sampling to obtain information from doctors with as varied background and experience as possible. Six groups accepted the invitation, one group did not answer. Two groups of interns (17 participants), one group of residents (eight participants) and two groups of partners (13 participants) attended. The last group consisted of three residents and nine partners. The supervisor of interns and residents did not participate in the focus group sessions. The participants included 20 female and 30 male doctors. Twenty-nine had graduated from Norwegian medical schools; 21 had graduated from medical schools in seven other European countries. Among the partners, 16 had worked more than 10 years as a specialist in general practice. Eighteen physicians practised in rural communities with less than 10000 inhabitants. These participants did not differ from the rest with respect to background and clinical experience. Twenty-one worked in communities with between 10000 and 20000 inhabitants, while 11 worked in towns with more than 20000 inhabitants. One participant practised alone, the rest worked in group practices.

Having conducted six groups with 50 physicians, we experienced data saturation regarding the topic on lifestyle counselling. We realised that we also had abundant examples of group interactions regarding the case story discussions.

To initiate a dialogue in the focus groups we used the Critical Incident Technique. ${ }^{20}$ According to this procedure, we invited the participants to present case stories from their own practice about lifestyle counselling which ended up as either a success or a failure. The group members commented on each story, and shared similar or contrasting experiences. We used no interview guide. The first author audiotaped and conducted the group sessions and made field notes at the end of each session to supply transcripts. An observer, a sports scientist, also made field notes, summarised his impressions and asked for comments at the end of each session to avoid misunderstandings. We considered audiotape recordings to provide sufficient information to study verbal interaction.

The first author, an experienced GP, transcribed the audiotapes verbatim. We used Systematic Text Condensation and an editing analysis style in analysis. ${ }^{21}{ }^{22}$ Bracketing preconceptions, we first read the material searching for an overall impression. The first and third author independently examined the text for units of meaning representing interaction and process in the presentation and discussion of case stories. We coded and grouped these units, contrasted and abstracted the content in each group, and finally discussed and summarised the content of each group into generalised descriptions of aspects of interaction. If illustrating quotes included more than one participant, we used fictitious names to identify the participants.

We analysed interactions among the participants when they presented and discussed case stories about lifestyle counselling.

\section{RESULTS}

\section{A different storyline of case presentations}

Some of the participants presented condensed case histories, focusing on objective data including results of measurements, laboratory tests and supplementary investigations. They described treatment outcomes in a similar brief and objective way. The other group members seldom interrupted these presentations, but asked questions and made comments after the case presentation. Other stories were more detailed and expansive. In these sequences the storytellers presented their own attitudes, emotions and reflections as well as their patients'. The other group members often made comments and asked questions during these detailed case presentations, and in this way co-authored the story. 
These stories often involved other aspects of the patients' histories than the particular medical problem in question. Tom, an experienced partner, told about his strategy when talking to patients who relapsed after smoking cessation:

Tom: I try to motivate those who have quit smoking, and remind them that it is great that they have managed to quit. Don't forget it.

Ben: Many times, and for those who have had a relapse, remind them that they have succeeded once.

Sandra: Yes, that's right. Focus on what you [the patient] did to succeed.

Tom: Focus on what went wrong, what happened, and how we can prevent it from happening again.

\section{Discussing and solving disagreements}

The case stories elicited discussions about how to handle clinical problems, the feasibility of clinical guidelines, checklists and evidence based medicine. The participants carefully suggested different counselling approaches, their own experience in similar situations and commented politely on the proposals suggested. When disagreements occurred, we observed moderate competition about being right, but the groups often reached mutual agreement. A few times disagreement was solved by referring to clinical guidelines. The participants often asked the rest of the group for advice, reflected upon ethical implications and discussed cooperation with other healthcare providers. John, a male resident told a story about treating a patient with obesity:

Kate: You measured weight now and then?

John: Yes, in the beginning we did. We observed a nice reduction. It was the start of a successful story which is unusual.

Conductor: What do you think about measuring weight in such consultations?

Kate: I actually ask the patients about that, whether they want to be weighed or not. I think weighing is ambiguous, get stuck to numbers. Weight does not always tell you about how the body changes.

John: Use waist circumference.

\section{Case-based thinking}

The case presentations initiated detailed discussions about the patients' agendas. The participants discussed what they believed to be the particular patient's expectations about the consultation, and the doctor's involvement. Some compared their patients' situation with their own. The storyteller explained the sources of the patients' motivation for change of lifestyle, and gave background information about the patients' experiences and identity beyond the medical problem in question. The groups discussed how this information could be utilised in the consultation:

I had a patient who actually succeeded in losing weight. She was about 35 years old. What made her succeed was that abdominal plastic surgery to remove excessive skin folds should be paid for when her body mass index was normalised. That was her motivation, to be operated and being able to wear bikini again. (Female resident)

Detailed information about the patients initiated reflections among group members about the complexity of many patients' lives, their self-efficacy and motivation for lifestyle change despite these constraints. Several expressed respect and admiration of how their patients managed their lives:

It is actually fascinating how much power that might be hidden behind rather poor facades. A complicated family situation, severe obesity, unemployment. Actually problems from A to Z. (female partner)

Some participants defended their patients if other group members criticised or cracked jokes about them during case discussions. Paula, a female intern presented a case story of a man taking anabolic steroids:

Ann: What kind of education or work did he have?

Paula: I don't remember.

Ann: Security guard, maybe?

Mike: You are rather stereotype!

Ann: No, do you think he had any education?

Paula: No, I don't think so, but he was employed in sales business. He seemed quite bright when I talked to him.

In other situations, the doctors supported each other's denigration of patients. Some case stories included patients who did not comply with the doctors' proposals, even when non-compliance would imply a serious threat to the patient's health. The participants commented on how patients fooled themselves, made unwise decisions or proposed too easy solutions to solve complex problems. A group of partners discussed patients' selfreported dietary habits:

Kate: The problem was that she ate next to nothing. She did everything right.

Peter: It's amazing. All of my obese patients belong to the group that tell they never eat much.

Rose: They know they are lying. 
Peter: Just let them write down what they eat for three days. Make an agreement about three normal days.

\section{Reflections about the professional role}

The case stories initiated discussions of meta-perspectives. The participants commented on the storyteller's professional behaviour, and how this behaviour affected the consultations and the patients. The participants shared professional knowledge concerning medical ethics and the need to tailor counselling to each patient. Stories about consultations that failed led to discussions about how to elicit the patient's agenda, the fear of provoking distrust, and the problem of unintended intimidation of patients when approaching the patients' deeply rooted habits.

Maybe you do everything right. Then you end up by not giving him the responsibility, in a way. In such a situation I would use the fatalistic part of me, and tell him that he was responsible. Sometimes maybe we are too eager, and take the responsibility from the patient. (Male partner)

\section{Peer support}

Several participants told about counselling that failed. This comprised complex situations when both the doctor and the patient despaired, but also consultations in which the doctors made proposals or decisions they later regretted. Some expressed significant emotional involvement and personal disappointment when communication failed, others told about their own struggle with lifestyle. The participants shared frustration related to insufficient support from specialised healthcare, reluctant patients and difficulties in doctor-patient communication. Discussing these narratives, peer-group members offered care and support, but they also gave constructive critique and suggested alternative solutions. They often responded by telling about similar experiences, and argued that doctors should expect limited success in consultations with patients with complex problems:

Rose: I thought about it after she had been there, that fifteen or twenty minutes-she should have fifteen or twenty minutes to solve each of those problems.

Jane: It can be too much for a GP, when specialist health care tells you to follow up every patient.

Edith: But we should not solve everything. I have low ambitions about solving other people's health problems.

\section{Informal associations}

The informal atmosphere in the peer groups allowed spontaneous associations and proposals, including suggestions about how to organise healthcare and ideas about alternative ways of counselling patients. The participants joked and told anecdotes, triggered by the case discussions and personal experiences from their own private and professional life. A group of residents discussed repetitively reminding patients to quit smoking:

Eric: Just mention smoking when they come in. I think it enhances motivation in the long run. My dentist has asked me every year if I use fluoride, and I don't. But the last two months I have used it, because he asked again. He has not done anything but ask me every time I met him.

Ruth: Same with me, but I have not managed yet.

Peter: Isn't it better to use dental floss?

Eric: But who uses dental floss?

Ruth: I'm thinking about it (laughter).

\section{DISCUSSION}

\section{Short summary of the main findings}

The storyline of case presentations in focus groups included detailed stories with emotional engagement and co-authoring from other group members. The group interaction initiated discussions about the patients' and doctors' behaviours and agendas in the consultations, ethical implications and the handling of clinical problems in everyday practice. The case stories inspired group members to reflect upon the complexity of counselling and the doctors' roles. The participants offered each other constructive critique and peer support.

\section{Strengths and weaknesses}

The presence of the researchers in the focus groups may have influenced what group members chose to tell. ${ }^{23}$ To reduce this influence, the conductor chose a withdrawn position, and seldom interrupted the group discussions. Being a peer may elicit information that would not be told to a researcher with a different background, ${ }^{24}$ but may also cause blindness to aspects of the discussions that a researcher with different background would see. This was compensated to some extent by the presence of an observer with another professional background. The group members knew each other quite well, and we conducted the group sessions in a scheduled meeting. The participants discussed real case stories from their own practice. This strengthens the validity of the study. Video recordings would have provided more information about non-verbal communication, but also increased the possibility of information overload.

\section{Dialogical interaction}

Some of the case stories followed the traditional, succinct storyline of case presentation, while expansive stories represented a different genre, with more focus on the patients' life context. We observed co-authoring during the expansive case presentations. In focus groups the audience may interact with the speaker by verbal 
interruption, exclamations, supportive or confronting utterances and non-verbal communication. The speaker may address the whole group, or a selected person. Moments of 'split floor' discussions occur when different subgroups speak together. Polyphonic discussions occur when several participants take part in the same discussion. There may be moments of silence when nobody wants or dares to 'take the floor' ${ }^{25}$ In this study we observed 'split floor' and polyphonic discussions, but no long periods of silence. This may be because the participants knew each other well, and the topic was engaging.

\section{Frames of interaction}

Prepared, condensed presentations represents front stage communication, ${ }^{26}$ also described in studies of morning reports in hospitals. ${ }^{2} 27$ In front-stage communication, the 'actor' plays the expected role. Front-stage communication can be presented to anyone. Detailed case stories with emotional engagement that admit uncertainty or failure, represent back-stage communication. ${ }^{26}$ This is not meant for outsiders, and occurs only in a safe environment. Professional back-stage communication is included in the hidden curriculum of medical education. ${ }^{28}{ }^{29}$ Humans socialise into groups that share social knowledge and communication. ${ }^{30} 31$ Peer groups of GPs share professional competence, experience and social roles. Socially shared knowledge is formed and maintained through dialogical communication, and shapes what is being spoken about and the manner by which contents are framed. ${ }^{7}$ We observed that this influenced how group members spoke about patients, other professionals and governmental institutions.

\section{An arena for testing out communications strategies}

We noticed spontaneous associations, jokes about patients and anecdotes about controversial behaviours of doctors, reflecting an informal, supportive back-stage atmosphere and group affiliation. We also observed attempts to try out controversial statements. Testing out the limits of acceptable behaviour is a frequent strategy in dialogues. While people talk to each other, they simultaneously carry out internal dialogues to prepare for positioning themselves in the discussion. ${ }^{7}$ A participant may not wish to reveal her true opinion, be humiliated or step out of the group. This can be solved by using incomplete utterances, jokes, quoting 'third parties' and prompting for collaborative utterances. ${ }^{32}$ Disrespectful comments about patients in some instances initiated constructive critique and a reminder of the ethical behaviour. The discussions addressed moral perception and the ability to identify ethical aspects in clinical situations. ${ }^{33}$ Some participants talked about their own struggle with lifestyle. Several narratives concerned counselling that failed. The group members trusted each other, and utilised the peer group as an arena of debriefing and peer support. Brondt et $\mathrm{al}^{34}$ found that participation in peer groups as part of CME was associated with decreased risk of professional dysfunction among Danish GPs.

\section{Facilitating person-focused care}

The atmosphere in the focus groups was supportive. The participants presented and discussed case stories in a cautious tone. By presenting their stories, they also presented themselves, thereby putting their own engagement at stake. The participants discussed patients' behaviour on a distanced level, but also demonstrated close, personal emotional involvement in patients' life world, and intentions of exploring patients' agenda. A distinction exists between patient-centred care and person-focused care. Person-focused care is based on accumulated knowledge of individuals, which provides the basis for better recognition of health problems over time, and facilitates appropriate care. ${ }^{35} 36$ We have used the concept 'case-based thinking' to signify how a casebased approach expands the emphasis on medical knowledge and the clinical problem in question, to encompass the context and the personal and emotional involvement where only thin layers of distance exist between the GP and the patient. Dialogues among GPs based on 'case-based thinking' may have consequences for how GP relate to the clinical problem in question, and to how disagreements are solved. We only observed moderate competition about being right, and the group members often asked each other for advice. They often reached mutual agreement, and discussed ethical implications of their actions.

\section{Implications for practice and research}

The case stories led to discussions about best practice and exchange of useful tips. The starting point of the discussions was not theory or research evidence, but clinical experience. However, in some situations the participants referred to clinical guidelines to solve disagreements. Peer-group meetings are suitable for introduction of attempts to improve practice skills. ${ }^{37} 38$ The storyteller tradition of case stories put clinical problems into context, and seemed to promote mutual reflections about counselling that might enhance meaning-making and reflective practice. ${ }^{39}$ We still need more information about how doctors think and learn, and how they develop and change clinical skills. Such information is available from peer groups of doctors.

\section{CONCLUSION}

Presentations and discussions on case stories in peer groups of GPs followed a detailed storyline, and initiated dialogues that highlighted patients' perspectives and facilitated learning, discussions of best practice and reflections on medical ethics. The safe backstage atmosphere permitted the GPs to express emotions and peer support, and to test out ideas and opinions. The interactions facilitated sense-making and meaning-making and influenced socially shared knowledge within the group. 
Acknowledgements Thanks to the colleagues who participated in the focus groups, and to John Johansen who assisted as observer in the focus group discussions.

Contributors EA and PS prepared the study protocol. EA collected the data. All authors were involved in analysis, interpretation and drafting the manuscript. EA is the guarantor.

Funding The study was supported by the Norwegian Medical Association's Fund for Research in General Practice.

Competing interests None.

Ethical approval The study did not involve patients. The doctors presented all case stories anonymously. The Regional Committee for Ethics in Medical Research regarded the study not to be within their mandate. All participants signed a declaration of informed consent before participation.

Provenance and peer review Not commissioned; externally peer reviewed.

Data sharing statement We have previous published two papers from this study: Lifestyle consultation in general practice-the doctor's toolbox: a qualitative focus group study, published in Fam Pract $2011 ; 28: 220-5$. Power and powerlessness: GPs narratives about lifestyle counselling. Br J Fam Pract 2012;62:160-6.

\section{REFERENCES}

1. Matalon A, Calo $\mathrm{H}$, Yaphe J. The role of the staff meeting in resolving professional dilemmas in family medicine: concealing a diagnosis. Eur J Gen Pract 2004;10:35-6, 40

2. Apker J, Eggly S. Communicating professional identity in medical socialization: considering the ideological discourse of morning report. Qual Health Res 2004;14:411-29.

3. Anspach RR. Notes on the sociology of medical discourse: the language of case presentation. J Health Soc Behav 1988;29:357-75.

4. Hill RF, Tyson EP, Riley HD Jr. The culture of morning report: ethnography of a clinical teaching conference. South Med $J$ 1997;90:594-600.

5. Gross CP, Donnelly GB, Reisman AB, et al. Resident expectations of morning report: a multi-institutional study. Arch Intern Med 1999;159:1910-14.

6. Charon R. Narrative medicine: honoring the stories of illness. Oxford: Oxford University Press, 2006.

7. Marková I. Dialogism: interaction, social knowledge and dialogue. In: Marková I. ed. Dialogue in focus groups. London: Equinox Publishing Ltd, 2007.

8. Rommetveit R. On message structure: a framework for the study of language and communication. Londonand New York: Wiley, 1974.

9. Malhotra A, Gregory I, Darvill E, et al. Mind the gap: Learners' perspectives on what they learn in communication compared to how they and others behave in the real world. Patient Educ Couns 2009;76:385-90.

10. Srinivasan M, Wilkes M, Stevenson F, et al. Comparing problem-based learning with case-based learning: effects of a major curricular shift at two institutions. Acad Med 2007;82:74-82.

11. Launer J. Moving on from Balint: embracing clinical supervision. $\mathrm{Br} J$ Gen Pract 2007:57:182-3.

12. Treweek S, Flottorp S, Fretheim A, et al. Hva gjør fastleger for å holde seg faglig oppdatert? [What do general practitioners do to keep themselves up to date?]. Tidsskr Nor Laegeforen 2005;125:304-6.

13. Rabinowitz S, Maoz B, Weingarten M, et al. Listening to patients stories. Storytelling approach in family medicine. Can Fam Physician 1994;40:2098-102.

14. Premi J, Shannon S, Hartwick K, et al. Practice-based small-group CME. Acad Med 1994;69:800-2.
15. Armson $\mathrm{H}$, Kinzie $\mathrm{S}$, Hawes $\mathrm{D}$, et al. Translating learning into practice: lessons from the practice-based small group learning program. Can Fam Physician 2007;53:1477-85.

16. Pereles L, Lockyer J, Fidler H. Permanent small groups: group dynamics, learning, and change. J Contin Educ Health Prof 2002;22:205-13.

17. Peloso PM, Stakiw KJ. Small-group format for continuing medical education: a report from the field. $J$ Contin Educ Health Prof 2000;20:27-32.

18. Eliasson G, Mattsson B. From teaching to learning. Experiences of small CME group work in general practice in Sweden. Scand J Prim Health Care 1999;17:196-200.

19. Abildsnes E, Walseth LT, Flottorp SA, et al. Lifestyle consultation in general practice - the doctor's toolbox: a qualitative focus group study. Fam Pract 2011;28:220-5.

20. Bradley CP. Turning anecdotes into data-the critical incident technique. Fam Pract 1992:9:98-103.

21. Miller WL, Crabtree BJ. Clinical research. A multimethod typology and qualitative roadmap. Doing Qualitative Research. 2 edn. Thousand Oaks, CA: Sage, 1999: 20-4.

22. Malterud K. Shared understanding of the qualitative research process. Guidelines for the medical researcher. Fam Pract 1993;10:201-6.

23. Coar L, Sim J. Interviewing one's peers: methodological issues in a study of health professionals. Scand J Prim Health Care 2006;24:251-6.

24. Chew-Graham CA, May CR, Perry MS. Qualitative research and the problem of judgement: lessons from interviewing fellow professionals. Fam Pract 2002;19:285-9.

25. Gossen M. Dialogical analyses of focus groups: data and analytical approaches. In: Marková I. ed. Dialogue in focus groups. London: Equinox Publishing Ltd, 2007.

26. Goffman E. The presentation of self in everyday life. New York Doubleday, 1959.

27. Mishler EG. Discourse of medicine: dialectics of medical interview. Norwood, NJ: Ablex, 1884.

28. Wear D, Aultman JM, Varley JD, et al. Making fun of patients: medical students' perceptions and use of derogatory and cynical humor in clinical settings. Acad Med 2006;81:454-62.

29. Bennett N, Lockyer J, Mann K, et al. Hidden curriculum in continuing medical education. J Contin Educ Health Prof 2004;24: 145-52.

30. Weber M. Wirtschaft ung Gesellschaft. Tübingen: J.B.C. Mohr, 1976.

31. Bourdieu P. Meditasjoner (Méditations pascaliennes). Oslo: Pax forlag A/S, 1999.

32. Marková I. Themata in dialogue: taking social knowledge as shared. In: Marková I. ed. Dialogue in focus groups. London: Equinox Publications Ltd, 2007.

33. Vetlesen AJ. Perception, empathy, and judgement: an inquiry into the preconditions of moral performance. University Park, PA: The Pennsylvania University Press, 1994

34. Brondt A, Sokolowski I, Olesen F, et al. Continuing medical education and burnout among Danish GPs. Br J Gen Pract 2008;58:15-19.

35. Starfield B. Is patient-centered care the same as person-focused care? Perm J 2011;15:63-9.

36. Meador BT, Rogers C. Person-centered therapy. In: Corsini RJ. ed Current psychotherapies. 2 edn. Itasca, Illionois: F.E. Peacock Publishers, 1979: 131-84.

37. Frich JC, Hoye S, Lindbaek M, et al. General practitioners and tutors' experiences with peer group academic detailing: a qualitative study. BMC Fam Pract 2010;11:12

38. Straand J, Fetveit A, Rognstad S, et al. A cluster-randomized educational intervention to reduce inappropriate prescription patterns for elderly patients in general practice-The Prescription Peer Academic Detailing (Rx-PAD) study [NCT00281450]. BMC Health Serv Res 2006;6:72.

39. Schön DA. Educating the Reflective Practitioner. Toward a new design for teaching and learning in the professions. San Fransisco: Jossey-Bass, 1987. 